\title{
Árvores urbanas em São Paulo: planejamento, economia e água
} MARCOS BUCKERIDGE ${ }^{I}$

\section{Árvores urbanas}

1 EXISTÊNCIA de árvores em regiões urbanas tem uma série de vantagens. Árvores podem cortar a incidência da luz em mais de 90\%, diminuindo a temperatura e a luz direta sobre quem caminha ou se exercita sob elas. Isso porque áreas cobertas com árvores alteram o conforto térmico em cidades (Martini, 2013; EPA, 1998). As árvores também filtram a poluição de material particulado, o que pode causar doenças pulmonares (Nowak et al., 2014). Além dos benefícios diretos para a sociedade, há também os indiretos: as árvores controlam o fluxo de água entre solo e atmosfera. Isso quer dizer que um grande conjunto de árvores pode produzir um "rio aéreo", liberando para a atmosfera grande quantidade de vapor de água em conjunto com compostos orgânicos voláteis que interferem na formação de nuvens.

Pela manhã, ao iniciar a fotossíntese, as árvores sugam a água do solo, água essa que é distribuída por toda a planta ao longo do dia. Ao mesmo tempo, as folhas sugam o $\mathrm{CO}_{2}$ da atmosfera e, para fazer isso, elas têm que manter abertos seus estômatos, que são aberturas que ficam na parte de baixo de cada folha. Uma única folha de jatobá, por exemplo, pode ter mais de 50 mil estômatos. Dessa forma, as folhas perdem vapor de água por evaporação ao longo de todo o dia e a água do solo forma uma coluna de ligação direta com a atmosfera. Esse fenômeno é chamado de evapotranspiração. Para se ter uma ideia das implicações desse fenômeno, uma única árvore de grande porte pode transpirar 150 mil litros de água em um ano, ou seja, uma média de 400 litros por dia (Kline et al., 1970).

Assim, para funcionar, as árvores de ambientes urbanos prestam serviços importantes para a cidade, sequestrando carbono em sua madeira, ao mesmo tempo que tornando o ar na cidade mais fresco, úmido e menos poluído (Figura 1).

Em um solo sem árvores, o tempo de residência de uma molécula de água na superfície pode ser da ordem de minutos ou dias. Mesmo que a água não entre na árvore, ao penetrar o solo em seu entorno, a temperatura menor na superfície fará que o tempo de residência da água aumente significativamente. Já se uma molécula de água for absorvida pela raiz da árvore, ela terá que seguir um caminho bem mais longo por entre as células e tecidos da planta até voltar à atmosfera através de um estômato aberto. Portanto, até que tudo isso aconteça, a molécula de água poderá ficar dias ou até semanas dentro do planta antes de sair para a atmosfera. Muitas moléculas de água ficarão presas no corpo 


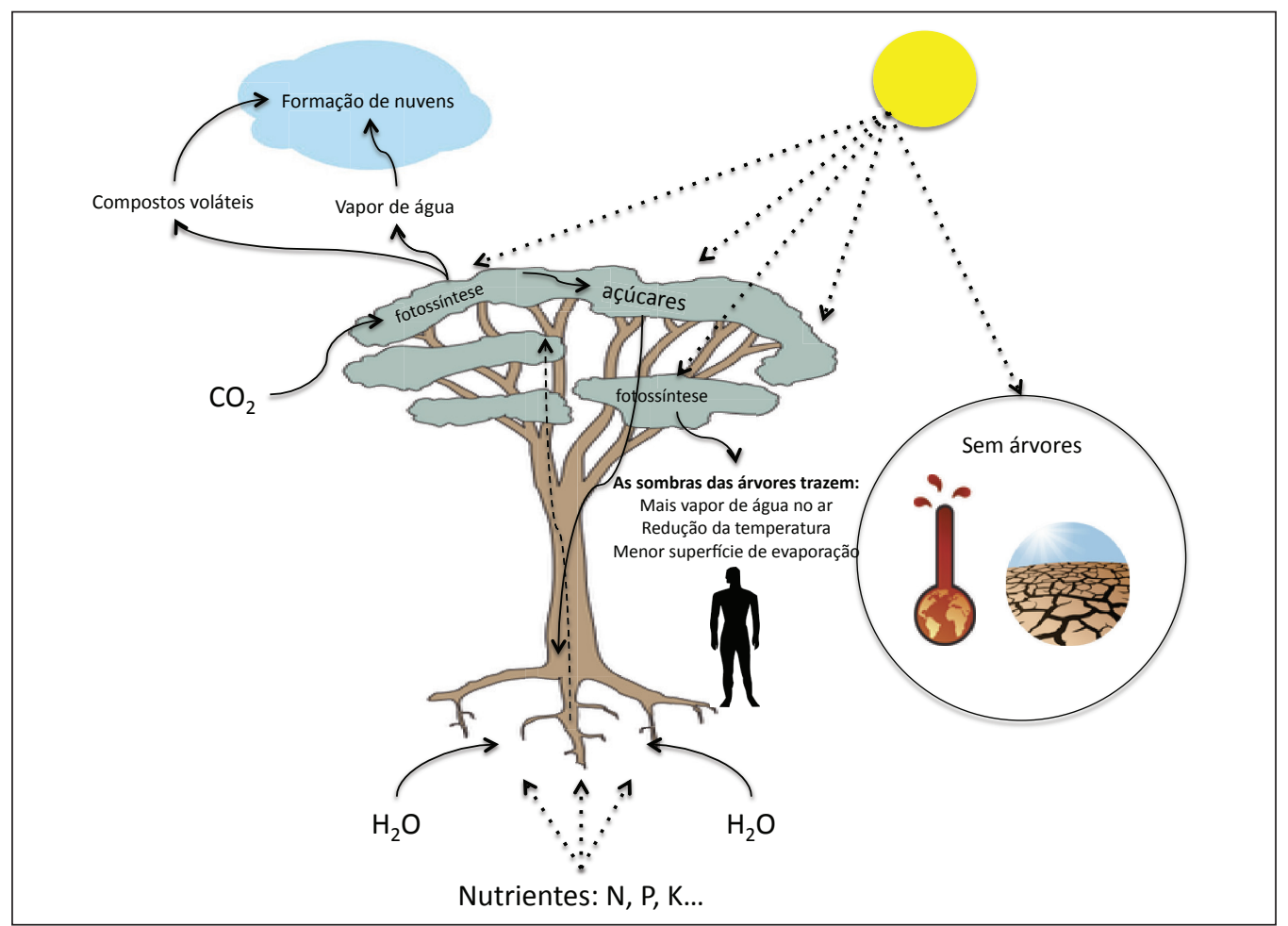

Figura 1 - Esquema geral do funcionamento de uma árvore e seu impacto na água na atmosfera.

da planta pelo resto de sua vida, caso sejam utilizadas para formar as ligações entre açúcares como a celulose. Isso ilustra o fato de que a água é fundamental para o sequestro de carbono pelas plantas. Pode-se dizer ainda que há também um "sequestro de água”, pois se considerarmos que o teor de água nas plantas corresponde a mais de $90 \%$ de seu peso, há um enorme e constante estoque de água nos corpos das árvores. Veja o Box para um aprofundamento sobre como as árvores funcionam.

Para a saúde humana, as árvores urbanas podem trazer muitos benefícios. Em um estudo com modelagens feitas para dez cidades americanas, Nowak et al. (2013) apontaram que elas são capazes de remover da atmosfera material particulado em grandes quantidades. Somente em Nova York, de acordo com o modelo, a retirada desse tipo de material atribuída às árvores urbanas teria levado a uma economia de US\$ 60,1 milhões e teria evitado a morte de 7,6 habitantes em um ano.

Há também benefícios menos palpáveis, mas não menos desprezíveis da presença das árvores no meio urbano. Pesquisas mostram que pessoas que vivem em cidades arborizadas têm menor tendência ao estresse e à depressão. Podemos assim dizer que uma cidade arborizada seria mais tranquila e teria moradores mais felizes e menos ansiosos (Gilchrist, 2015). 
As árvores urbanas são também importantes na adaptação aos impactos das mudanças climáticas. Estas últimas são o resultado da elevação da temperatura em razão das emissões de $\mathrm{CO}_{2}$ ligadas às atividades humanas. No último relatório do Painel Intergovernamental de Mudanças Climáticas publicado em 2014, dois dos quatro impactos apontados como os mais importantes para a América do Sul estão relacionados com: 1) as alterações nos níveis de água, com extremos de excesso e escassez e 2) o possível aumento em doenças infecciosas em razão da combinação de elevação de temperatura e alterações hídricas drásticas (Magrin et al., 2014). Para o Brasil, e mais especificamente na região Sudeste, um bom exemplo desse tipo de impacto tem sido a dengue, que se apresentou como uma epidemia em 2014 em São Paulo. Nesse caso, o aumento na dengue parece estar correlacionado com a crise hídrica, mas ainda não se sabe ao certo se essa é mesmo a explicação e tampouco se sabe se ambos poderiam ser considerados impactos das mudanças climáticas. No entanto, a epidemia de dengue em 2015 em São Paulo ilustra bem o potencial que mudanças no clima podem ter na elevação de casos de doenças infecciosas em regiões metropolitanas.

Além de problemas de saúde desse tipo, gastaremos também uma fortuna para equipar e manter hospitais e serviços médicos para a população maior de idosos que deveremos ter por volta de 2050. Isso porque idosos são proporcionalmente mais sensíveis aos extremos de seca e temperatura, especialmente se combinados com a poluição existentes nas cidades atualmente (Saldiva, 2008). As árvores, com seu poder de amenizar efeitos de temperatura e de seca, podem ter um papel importante como medidas preventivas de problemas relacionados ao envelhecimento da população da cidade de São Paulo.

Por tudo o que foi exposto aqui, que é somente uma parcela dos benefícios que as árvores trazem às cidades, pode-se dizer que, abrindo o nosso "guarda-chuva verde" de árvores agora, e de forma estratégica, estaríamos garantindo a minimização dos impactos negativos causados pelo aumento de temperatura nos próximos vinte a trinta anos.

\section{Árvores nas grandes metrópoles: São Paulo como estudo de caso}

Compreender a importância das árvores em ambientes urbanos de grandes metrópoles é fundamental se considerarmos que o índice de urbanização na América Latina é um dos mais altos do planeta e que até 2040 chegaremos a 90\% dos habitantes vivendo em cidades (Magrin et al., 2014). No presente artigo, enfocaremos a cidade de São Paulo por suas características diversas e também por apresentar problemas relacionados a um desenvolvimento com pouca base de planejamento urbano cientificamente fundamentado no que concerne à arborização urbana. São Paulo fornece oportunidades para discutir problemas que já deveriam estar resolvidos - pelo menos já estão em muitas grandes cidades do mundo - ou bem encaminhados a esta altura, mas que ainda são timidamente ou não são sequer incluídas entre as políticas públicas para o desenvolvimento urbano da cidade. 
Outro ponto importante que favorece o foco na cidade de São Paulo é que muitos dos problemas de falta de planejamento no que concerne à arborização urbana têm como pano de fundo impactos antrópicos muito fortes sobre a cidade que já estão começando a se mesclar aos impactos das Mudanças Climáticas Globais (Marengo et al., 2013).

Na cidade de São Paulo a responsabilidade pela manutenção e remoção das 650 mil árvores plantadas nas ruas (comunicação pessoal) e outras tantas nos parques da cidade é da prefeitura municipal. Já as árvores dentro das propriedades são de responsabilidade dos moradores, mas esses não podem remover árvores a não ser que a prefeitura autorize mediante uma justificativa adequada. A metrópole paulistana também está envolvida por parques estaduais, que são de responsabilidade do governo do estado. Assim, em São Paulo praticamente toda política e todo controle das árvores presentes ou próximas ao ambiente urbano é de responsabilidade do poder público. Por um lado, essa forma de manejo facilita o planejamento, em razão da diminuição na complexidade relacionada à formulação e implantação de planos de médio e longo prazos. Por outro lado, depende também da prioridade que o poder público dá ao tema, o que pode variar de gestão para gestão. A maior centralização das decisões sobre as árvores seria uma vantagem se os governos considerassem a questão do planejamento de arborização urbana como uma atividade de estado e não de governo. Só assim seria possível dar a continuidade necessária aos projetos e obter os inúmeros benefícios que as árvores trazem para a metrópole.

Levando-se em consideração que árvores são seres complexos (veja o Box) e que têm esperança de vida muitas vezes similar ou até maior que a dos humanos, qualquer plano que se faça pode transcender gerações humanas. Portanto, ações de plantio de árvores urbanas precisariam ser submetidas a planejamento cuidadoso, fora dos tempos de governos, e tentando formular cenários de longo prazo que beneficiem as futuras gerações.

A recente crise hídrica e as fortes tempestades que atingiram a cidade de São Paulo no início do ano 2015 ajudaram a alertar durante algum tempo as autoridades e a população paulistana para a importância de planejar melhor a arborização urbana na cidade. Mas os problemas de quedas de árvores e os prejuízos causados, bem como a necessidade de planejamento de longo prazo são rapidamente esquecidos após a queda de intensidade de cobertura pela mídia, tornando a aparecer somente quando uma nova crise emerge.

Para se ter uma ideia geral da situação da arborização urbana na cidade de São Paulo, utilizamos dados divulgados pela prefeitura municipal de São Paulo sobre o Índice de Cobertura Vegetal (ICV).

Utilizando dados de Cobertura Vegetal obtidos por imagens de satélite - que detectam a cor verde - e dividindo esses valores de área pelo número de habitantes em cada região administrativa da cidade, foi possível observar que há uma distribuição bastante desigual do verde em São Paulo (Figura 2). 
Preto: regiões de alta prioridade 1 ( 3 a 8,4$)$ Vermelho: regiões de prioridade 2 ( 8,5 a 13$)$ Azul: regiões de prioridade 3 (13,1 a 22,5)

Perspectivas:

Para ter árvores adultas e podermos contar com áreas verdes adequadas, teremos que esperar pelo menos 20 anos. TEMOS QUE COMEÇAR AGORA A PLANTAR ÁRVORES EM SÃO PAULO, principalmente na Zona Leste

\section{Comentários}

1 -As regiões contornadas em PRETO estão na faixa de muitobaixo e baixo ICV. Portanto, é necessário ter metas mais arrojadas nestas áreas.

2 - A região contornada em VERMELHO tem baixo ICV e tem que ter também uma ação mais intensiva.

3 - As regiões contornadas em AZUL necessitam de ações em áreas específicas e manutenção (reposição) em sub-regiões com menos árvore.

Regiões como Butantã, Santo Amaro e Itaquera têm que ser vistas com mais detalhe. No Butantã, por exemplo, a USP é muito arborizada e causa diferenças. A Fazenda do Carmo também faz diferença em Itaquera. Regiões mais periféricas ao norte, sul e também no leste são influenciadas pelas Matas nativas em volta da cidade. É preciso olhar para as áreas urbanizadas para saber o real ICV.

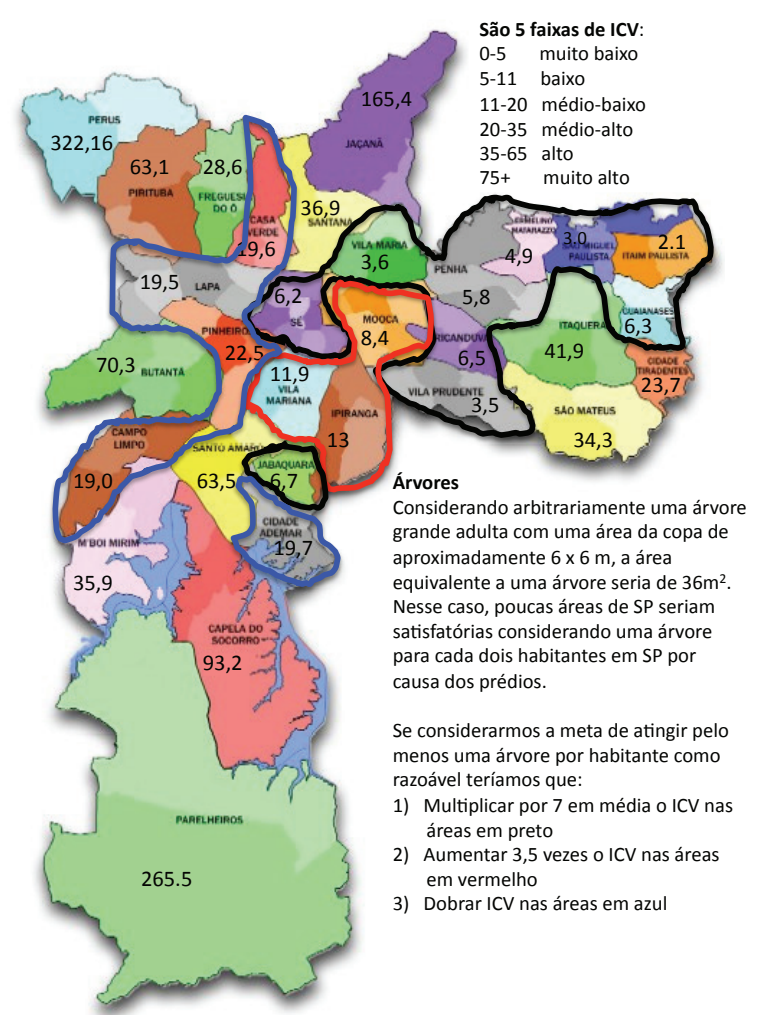

Fonte: Sec. Planejamento / Prefeitura de São Paulo. Disponível em: <http://www.prefeitura.sp.gov.br/cidade/secretarias/upload/planejamento/Verde\%2010_2013.xls>.

Responsável: Secretaria Municipal do Verde e do Meio Ambiente.

Figura 2 - Distribuição do Índice de Cobertura Vegetal (ICV) na cidade de São Paulo em 2012.

Enquanto algumas regiões mais periféricas apresentam altos valores de ICV, esses claramente afetados pela existência de resíduos de florestas ou parques estaduais próximos à cidade, certas regiões da metrópole não apresentam tanto essa influência. Regiões como Parelheiros, Cidade Ademar, Perus e Jaçanã são fortemente influenciadas pela Mata Atlântica ao sul da cidade e a Cantareira ao norte, e por isto têm altos ICV. Já o centro e a região leste se apresentam como zonas fortemente cinza, com ICV da ordem de 2 a $6 \mathrm{~m}^{2}$ de verde por habitante. Essa região, circundada em preto no mapa da Figura 2, apresenta o maior déficit de árvores da cidade de São Paulo. Para se ter uma ideia, se fizermos uma estimativa do número de árvores com base em verde utilizando o parâmetro de que a copa de um indivíduo adulto de Tipuana tipu - a espécie mais abundante na cidade - ocupa em média cerca de $36 \mathrm{~m}^{2}$ de área basal, apenas 6 das 28 regiões estão acima de 1 árvore por habitante (Tabela 1). Por outro lado, os $20 \%$ com o menor número de árvores por habitante encontram-se na Zona Leste da cidade. 
Tabela 1 - Estimativa do número de árvores por habitante em São Paulo em 2012 com base nos índices de cobertura verde obtidos por imagem de satélite. ${ }^{1}$

\begin{tabular}{|c|c|c|c|}
\hline Região de SP & Habitantes & $\begin{array}{l}\text { Árvores } \\
\text { em SP }\end{array}$ & $\begin{array}{c}\text { Árvores por } \\
\text { habitante }\end{array}$ \\
\hline Itaim Paulista & 395976 & 23209 & 0.06 \\
\hline São Miguel & 414063 & 34620 & 0.08 \\
\hline Vila Prudente/Sapopemba & 551894 & 54116 & 0.10 \\
\hline Vila Maria/Vila Guilherme & 320730 & 31806 & 0.10 \\
\hline Ermelino Matarazzo & 219663 & 30021 & 0.14 \\
\hline Penha & 497364 & 80683 & 0.16 \\
\hline Sé & 385348 & 66151 & 0.17 \\
\hline Guaianases & 284795 & 49602 & 0.17 \\
\hline Aricanduva/Formosa/Carrão & 273893 & 49072 & 0.18 \\
\hline Jabaquara & 227565 & 42226 & 0.19 \\
\hline Moóca & 313491 & 73148 & 0.23 \\
\hline Vila Mariana & 315303 & 104225 & 0.33 \\
\hline Ipiranga & 449942 & 162979 & 0.36 \\
\hline Campo Limpo & 561284 & 296545 & 0.53 \\
\hline Lapa & 275616 & 149445 & 0.54 \\
\hline Casa Verde/Cachoeirinha & 335479 & 182556 & 0.54 \\
\hline Cidade Ademar & 409167 & 224019 & 0.55 \\
\hline Pinheiros & 271203 & 169728 & 0.63 \\
\hline Cidade Tiradentes & 209694 & 138223 & 0.66 \\
\hline Freguesia/Brasilândia & 431473 & 336309 & 0.78 \\
\hline São Mateus & 418263 & 398512 & 0.95 \\
\hline Mboi Mirim & 544309 & 543402 & 1.00 \\
\hline Santana/Tucuruvi & 333659 & 341537 & 1.02 \\
\hline Itaquera & 530038 & 616316 & 1.16 \\
\hline Santo Amaro & 224046 & 395379 & 1.76 \\
\hline Pirituba & 421877 & 750707 & 1.78 \\
\hline Butantã & 414767 & 809948 & 1.95 \\
\hline
\end{tabular}


Em resumo, excluindo-se áreas fortemente influenciadas por remanescentes de florestas no entorno, a cidade de São Paulo hoje teria uma média estimada de 0,6 árvore por habitante, mas com uma distribuição heterogênea que varia de praticamente zero no Itaim Paulista (0,06 árvores por habitante) até um máximo de cerca de duas no Butantã. Assim, é necessária uma ação de planejamento de longo prazo que contemple o plantio de árvores para uniformizar a arborização para o mais próximo possível de uma árvore por habitante, elevando os níveis de arborização nas regiões central e leste principalmente.

\section{As árvores urbanas de São Paulo e a água}

Na cidade de São Paulo, a espécie mais abundante de árvore hoje plantada é a Tipuana tipu. Essa espécie é oriunda da região oeste da América do Sul, sendo portanto exótica, ou seja, não tendo a sua origem no Brasil. A tipuana foi trazida para São Paulo durante o primeiro quarto do século XX, quando houve a expansão organizada de novos bairros na cidade na qual a empresa inglesa City executou um plano de urbanização que deu origem a bairros hoje tradicionais, como Higienópolis, Pacaembu e Perdizes (Andrade; Coelho Jr., 2013). Nesse plano, a tipuana foi usada intensivamente na arborização urbana e, como a árvore cresce relativamente rápido e gera copas elegantes, outras ações de plantio de árvores, até recentemente, usaram a espécie. Em tempos modernos, as substituições estão sendo feitas por várias outras espécies, principalmente espécies nativas da região onde São Paulo se encontra.

Para se saber mais sobre a influência das árvores sobre o balanço hídrico em São Paulo uma pergunta importante a ser respondida é: quanta água uma grande árvore como uma tipuana, por exemplo, libera para a atmosfera?

Usando uma média de transpiração de $400 \mathrm{~L}$ por dia, que é a média para uma grande árvore de carvalho, como uma tipuana adulta, somente as $650 \mathrm{mil}$ árvores nas ruas de São Paulo transpirariam cerca de 260 mil metros cúbicos por dia. Considerando que um dia de $24 \mathrm{~h}$ tem 86.400 segundos, o conjunto de árvores em São Paulo teria uma "vazão" de três metros cúbicos por segundo de água em forma de vapor, o que equivale a cerca de $30 \%$ da vazão do rio Pinheiros ou $6,6 \%$ da vazão do rio Tietê. No entanto, temos que considerar que muitas das nossas árvores perdem folhas no inverno e com isto talvez esta "vazão" seja algo como a metade do potencial total anual se elas ficassem sempre com as folhas, ou seja, 15\% do Pinheiros e 3,3\% do Tietê. Em anos com inverno mais seco esse valor diminui, e quando é menos seco, aumenta.

Mas é preciso lembrar que nesse caso somente as árvores das ruas foram contadas. Se somarmos as dos parques e das florestas da Cantareira, da região de Parelheiros e outras ao redor de São Paulo, que abrigam milhões de árvores, podemos pensar que há muito mais água em forma de vapor sendo liberada sobre ou bem próximo à cidade.

$\mathrm{Na}$ Cantareira, por exemplo, estima-se que a densidade de árvores seja de 6.660 indivíduos por hectare (Arzolla, 2011) em uma área em regeneração. 
No entanto, de maneira geral, em uma floresta madura em área tropical estima-se que a densidade de árvores seja de cerca de 400 a 1000 árvores por hectare (Sagar et al., 2003; Dombro, 2015). Como a área coberta pela Cantareira é de aproximadamente 7900 hectares (ou $79 \mathrm{~km}$ quadrados), o potencial de transpiração estimado seria de cerca de 500 metros cúbicos, o que equivale a cerca de 25 vezes a vazão do Rio Tietê.

Esses são apenas cálculos estimados, mas por meio deles pode-se ver que há uma enorme quantidade de água associada às árvores na cidade de São Paulo. O impacto real desse rio aéreo e as possíveis relações com todo os sistema metropolitano ainda é matéria de estudos mais profundos e complexos, que certamente valem a pena ser feitos para que se montem planos de arborização urbana cientificamente embasados para a metrópole paulistana.

\section{Pontos importantes a considerar em um plano de equilíbrio da arborização em São Paulo}

Qualquer plano adequado de plantio de árvores deve levar em conta as características fisiológicas das espécies a serem plantadas. Mas isso é mais difícil no Brasil porque em uma região tropical como a nossa a diversidade de espécies é muito grande e há relativamente poucos estudos sobre elas. Há estudos notáveis e de grande importância, como o de Brazolin (2009) sobre a espécie Tipuana tipu em São Paulo. Mas se considerarmos o grande número de espécies que poderiam ser usadas em arborização em São Paulo, faltam bancos de dados que permitam um planejamento adequado e de qualidade, seguindo os moldes do que foi apresentado por Brazolin em 2009.

Ao mesmo tempo, é necessário conscientizar a sociedade sobre a importância das árvores, de forma que ela possa demandar mais estudos sobre a biodiversidade na região em que a cidade se encontra. Isso é importante porque se olharmos um mapa do sudeste do estado de São Paulo (Figura 3), vemos claramente que a expansão das cidades promove a abertura de vazios na floresta original. Ou seja, todas as nossas cidades tendem a provocar o mesmo impacto que São Paulo provocou em maior escala e a definição de políticas cientificamente embasadas poderia ter um impacto muito positivo no conjunto de cidades que se desenvolve paralelamente e tende a formar possivelmente uma supermetrópole no futuro. De fato, já se identificam claramente corredores cinza no triângulo formado por São Paulo-Campinas-Sorocaba. Mais ainda, esse corredor já chega a Americana e caminha em direção a Piracicaba.

Se no ambiente urbano tentássemos plantar espécies que já existem no entorno, com a máxima diversidade possível, poderíamos pensar na possibilidade de formar "corredores" para abrigar a biodiversidade de espécies animais e outras e com isso teríamos uma relação mais próxima com o sistema ecológico do entorno. Essa ideia pode ser controversa ou até futurista, mas temos que começar a pensar que talvez as cidades (ou os grandes conglomerados de cidades, como se vê no mapa da Figura 3) do futuro caminhem na direção de uma 


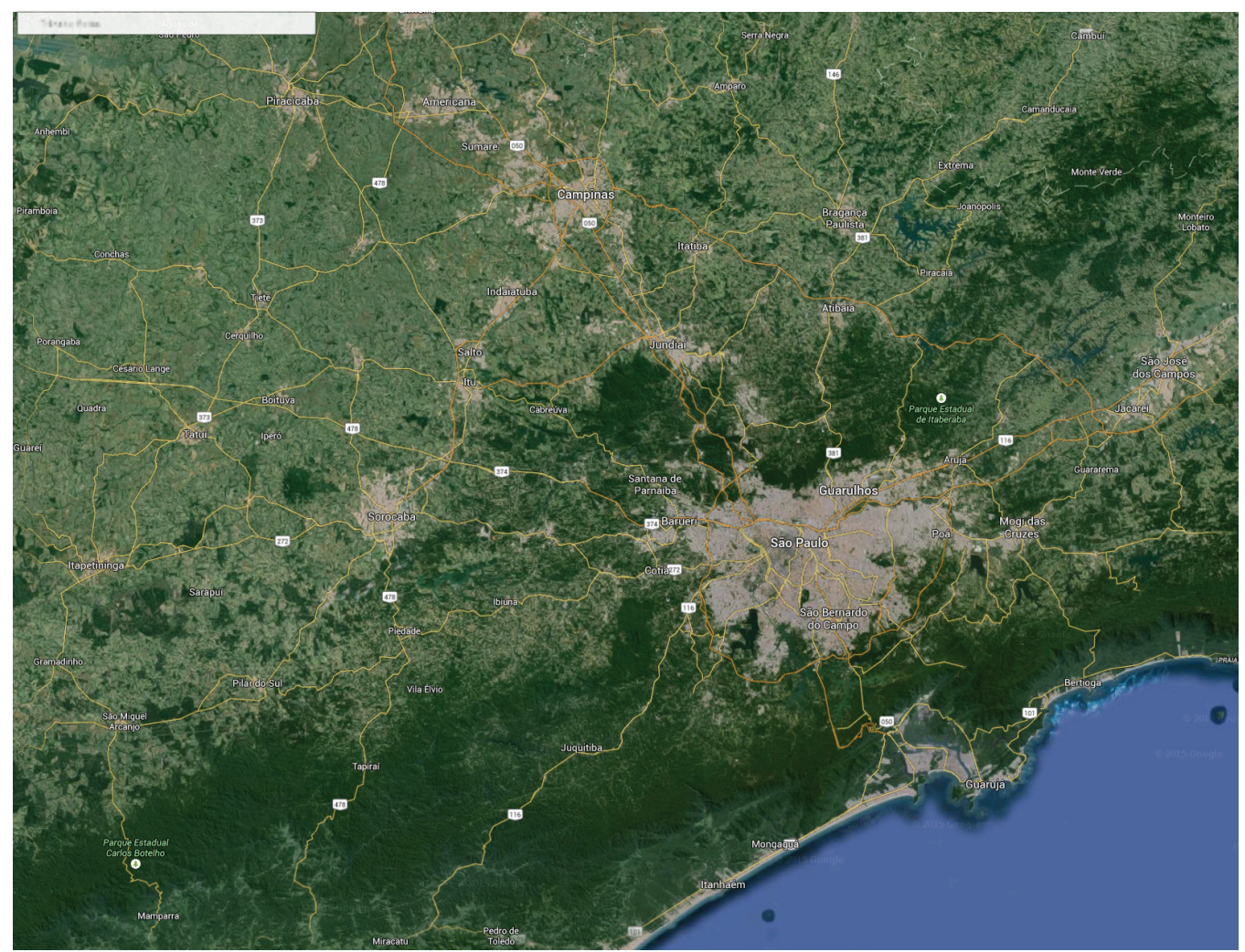

Figura 3 - Imagem da região sudeste do estado de São Paulo mostrando as drásticas diminuições em árvores nas cidades do eixo. Notar que dentro da Região Metropolitana se destacam algumas manchas verdes, notadamente o Parque do Estado e alguns bairros (Morumbi, Pinheiros, Lapa e Butantã, principalmente).

integração muito maior com o ambiente, trazendo de volta parte da biodiversidade que existia antes de a cidade ser formada. Os modelos de urbanização que temos no Brasil hoje não são compatíveis com essa ideia, mas já é tempo de começarmos a pensar se esse não seria o melhor caminho. A vocação ambiental do Brasil, especialmente das gerações que estão crescendo neste momento, favorece bastante essa possibilidade.

Neste momento, o que podemos fazer é apenas iniciar o processo. É impossível atingir um nível de impacto ambiental mínimo e ao mesmo tempo ter uma região urbanizada? Hoje parece utópico, pois há fatores econômicos, sociais e estruturas que têm um peso enorme sobre qualquer planejamento que se faça. Mas já seria um bom início passar a incluir a arborização urbana de forma mais séria em planos para o futuro da cidade de São Paulo. Para isso, é imperativo que seja adotada uma abordagem sistêmica aos problemas levando em consideração multifatores, como tem sido discutido por Sterman (2012).

A cidade terá sempre características artificiais, mas pode pelo menos tentar ser mais integrada à biosfera do que as cidades que temos hoje. Podem-se dimi- 
nuir os impactos de vários fatores ao mesmo tempo e conectar diversos serviços dos ecossistemas pela fusão de uma paisagem urbana com uma paisagem florestal.

\section{Como harmonizar o estilo de negócios e o meio ambiente na metrópole paulistana}

\section{Árvores e a economia}

As plantas são responsáveis pelo giro da economia no planeta. Elas assimilam o $\mathrm{CO}_{2}$ atmosférico através do processo de fotossíntese, transformando o carbono em compostos orgânicos que são a base de nossa comida, energia e materiais. Portanto, qualquer impacto sobre as plantas afeta indiretamente o homem.

Um estudo recente (Runfola; Hughes, 2014) comparando cidades "verdes" e "cinza" entre 373 cidades americanas concluiu que as cidades que têm maior foco em iniciativas econômicas são mais cinza, enquanto as cidades que têm maior foco em iniciativas de justiça social são mais verdes. Estas últimas, no entanto, são mais raras, perfazendo somente $11 \%$ das cidades analisadas pelos autores. São Paulo tem agido historicamente como uma cidade cinza. Mas é possível mudar, basta a população exigir um redirecionamento das políticas públicas no sentido de um equilíbrio melhor, e governos, empresas e terceiro setor se unirem em um plano que seja baseado numa abordagem sistêmica.

Uma mudança para um novo ponto de equilíbrio, deixando de ser tão cinza e ao mesmo tempo não abrindo mão dos ganhos econômicos, é não só possível, como benéfica para todos os habitantes de uma cidade como São Paulo. Mas para que a cidade de São Paulo se modernize e adote um estilo em que tanto a economia como o bem-estar e a justiça social se harmonizem será necessário resolver uma série de questões. Em seguida discutimos alguns exemplos.

\section{A cidade deve revitalizar suas áreas de várzea, como ocorreu}

em grandes capitais do mundo, ou é algo caro e inviável tecnicamente?

Se já foi feito em outras grandes capitais do mundo (Londres e Paris, por exemplo), não há nenhuma dúvida de que seja tecnicamente viável. São Paulo tem grande vocação para negócios e as pessoas que vêm para cá recebem uma lavagem cerebral dos próprios paulistanos de que esta é uma cidade feia, cinza, cheia de trânsito, violenta etc. Sabemos que isso não é inteiramente verdadeiro, mas quando uma ideia é contada repetidamente acaba sendo vista como verdade. Ter uma cidade organizada, arborizada e com projetos impressionantes de integração das áreas de várzea com a população pode atrair ainda mais negócios e fazer que o turismo de negócios deixe ainda mais dinheiro na cidade. $\mathrm{O}$ turista pode decidir trazer a família para visitar a cidade e com isso gastar mais aqui. Os próprios paulistanos ficarão mais na cidade a aproveitarão melhor São Paulo. Prevê-se que, até 2050, 90\% da população da América Latina viverão em ambiente urbano. Por isso temos que fazer que a cidade seja um lugar agradável onde se viver. Elas não podem ser apenas dormitórios e um conjunto de ruas para transitarmos para ir e vir do trabalho. Têm que ser mais do que isso, e é nossa responsabilidade fazer que as mudanças ocorram nas próximas décadas. 
Do ponto de vista da população, os benefícios da recuperação das várzeas são enormes. São Paulo é uma rede impressionante de rios, e apesar de ter sido fundada nessa região por causa dos rios, com o desenvolvimento viramos as costas para eles, os cobrimos e os poluímos. Escolhemos um caminho que levou ao realinhamento dos rios para fazer a água fluir mais rapidamente e evitar epidemias de doenças infecciosas no passado (Fioravanti, 2013). Mas hoje temos tecnologias que poderiam fazer que voltássemos em parte ao que tínhamos no passado. Milhões de paulistanos saem nos feriados em busca de proximidade a um ambiente aquático. São Paulo tem parte disso aqui mesmo, bem debaixo dos pés. Por que não usar? Pode ser caro, mas por que não vivermos bem? Em um lugar lindo, com lazer pleno e uma população mais feliz? Ainda, será que tudo isso não poderia ser transformado em negócios lucrativos? Em inovação? Essencialmente, São Paulo é uma espécie de grande várzea. Será que São Paulo não poderia recuperar a parte boa dela? Será que não poderíamos fazer isso de uma forma original, que mostrasse que é, sim, possível fazer melhor ainda do que Londres e Paris fizeram?

\section{Devemos entervar os cabos elétricos e de informação? \\ Isso seria uma necessidade pública?}

Sem dúvida, é uma necessidade pública. Talvez não seja economicamente viável tirar os fios de toda a cidade, mas podemos ampliar o máximo possível o pouco que já temos. Enterrar os fios tornará não somente mais fácil a manutenção, provavelmente diminuindo a taxa de roubo de cabos e certamente diminuindo os diversos problemas que temos tido com a arborização urbana, que tem que ser literalmente mutilada para dar passagem aos fios. Ao se mutilar uma árvore, se desequilibra muitas vezes a distribuição de pesos na copa, e com isso aumenta a probabilidade de queda. Acelera-se o envelhecimento das árvores, gerando custos altos relacionados à substituição de árvores com maior frequência. O potencial que as árvores têm de contribuir para o "rio aéreo" cai vertiginosamente e leva anos para se recuperar, causando assim um impacto negativo nas questões hídricas da cidade. Além disso, transforma-se algo belo em algo feio, na realidade grotesco! Sem os fios, as copas de árvores crescem de acordo com as suas características genéticas e se tornam copas bem mais estáveis e também exuberantes. Basta olhar ao redor, há vários exemplos na cidade. Outro ponto importante é a poluição visual. Por que precisamos conviver com algo tão feio? Por que as nossas cidades não podem ser bonitas e agradáveis? Uma paisagem agradável tem enormes vantagens de vários pontos de vista, como diminuição de depressão e violência, diminuição da agressividade, e também convida o cidadão a usar menos o automóvel para caminhar por seu bairro e/ou usar a bicicleta para trabalhar. Os ciclistas poderiam aproveitar ainda mais as rotas sem o calor escaldante de avenidas sem árvores. Por isso o efeito do embelezamento é, sim, uma necessidade pública. Como política pública, o embelezamento é também uma ação nos setores de saúde, segurança, educação e justiça social. 


\section{Parques e praças públicas: o setor privado deve interferir?}

O setor privado deve sim participar e a ideia de concessões pode ser um caminho. Isso porque o poder público tem grande dificuldade (financeira e logística) de dar conta de tudo o que precisa ser feito em uma cidade tão grande como São Paulo. O poder público poderia se restringir a fazer a coordenação de todo o processo, sempre ouvindo e mantendo transparência total para os habitantes de cada região. A cidade de São Paulo é um mosaico de situações com características muito diversas e por isso precisa de estudos específicos para cada caso. São Paulo se apresenta como uma grande oportunidade de desenvolver novas ideias e empresas podem ser instaladas e/ou criadas aqui, dando empregos e gerando inovação no setor urbano paulistano. Como São Paulo é uma metrópole única, projetos de sucesso daqui poderiam até se tornar produtos a serem aplicados em outras cidades do mundo, trazendo divisas e gerando mais empregos na própria metrópole.

Não parece possível abordar toda a cidade de uma única forma, com um único método. Como cada região tem suas peculiaridades, seria muito mais produtivo dar concessões a empresas que se dediquem a resolver os problemas de forma diferente, conforme a situação. Um problema, porém, é saber se temos ou não empresas preparadas para assumir isso. Assim, primeiramente teríamos que fazer um bom levantamento. Algumas experiências tiveram grande sucesso na cidade de São Paulo, como a intervenção que foi feita na Av. Braz Leme há alguns anos pela empresa TOTUS. Parte da avenida foi adotada pela empresa e passou de um simples canteiro no meio da avenida a um dos lugares mais agradáveis da cidade para caminhar, se exercitar e admirar um jardim bem planejado e bem cuidado. Há vários outros exemplos na cidade que podem ser usados como modelos para regiões similares. O poder público poderia fazer um estudo bem completo sobre como grandes cidades em países desenvolvidos lidaram e lidam com o verde urbano (o verde nos parques, praças, ruas etc.). Washington nos Estados Unidos, Paris na Europa, e Tóquio e Pequim na Ásia são boas opções. Podemos formar parcerias com cidades como essas para ajustar melhor a nossa situação aqui. Empresas estrangeiras poderiam também se interessar pelas concessões e com isso poderíamos aprender muito e adaptar boas experiências do mundo à nossa realidade. Se o poder público quiser levar à frente a questão do verde-urbano, isso deveria ser feito mediante algo como um Centro de Estudos, que possa analisar o problema cientificamente e trabalhar em conjunto com empresas, população e cidades parceiras, para aplicar as melhores ideias. São Paulo é a maior metrópole do planeta em região tropical. Não deveríamos ter as soluções mais espetaculares já vistas? Temos que ser ambiciosos e investir mais em inovações urbanas. Uma visão de futuro seria que os turistas um dia viessem a São Paulo só para ver os projetos mais criativos e interessantes de integração do verde à população já feitos por uma grande metrópole. 


\section{Biodiver-cidade: podemos viver melhor em São Paulo?}

As cidades podem ser vistas como sistemas complexos em que há uma janela de equilíbrio que permite a um grupo de seres humanos viver com relativo conforto. Para que isso ocorra, os subsistemas de uma cidade têm que funcionar de forma a manter o máximo nível possível de equilíbrio. Em uma grande metrópole como São Paulo, onde há um grande número de pessoas e um enorme conjunto de eventos acontecendo ao mesmo tempo, as decisões em cada subsistema têm que levar em consideração sempre o equilíbrio geral do sistema maior, a cidade. A cidade é como um grande organismo vivo e as árvores fazem parte desse sistema urbano complexo. Por isso, o pensamento sistêmico parece ser o melhor caminho a adotar para lidar com os problemas extremamente complexos que há se apresentam. Inserir a arborização urbana seriamente na agenda de planejamento para as próximas décadas é, sem dúvida, um ótimo negócio para as cidades brasileiras.

\section{Para saber mais sobre como as plantas usam a água e sequestram carbono}

Ao entrar nos cloroplastos (estruturas celulares que abrigam a clorofila e dão a cor verde às plantas) o $\mathrm{C}$, ou seja, carbono do $\mathrm{CO}_{2}$, é bioquimicamente ligado a compostos de carbono (ácidos) já existentes nas folhas, de forma que a cadeia de carbono vai aumentando até formar açúcares de 6 carbonos (a glicose e a frutose). Estes dois açúcares podem ser ligados entre si, formando sacarose e serem transportados para o resto da planta usar para crescer. Alternativamente, as glicoses podem ser encadeadas entre si e formam grânulos de amido que serão guardados para uso durante a noite ou no outro dia. A energia para fazer tudo isso vem da luz. A energia da luz é inicialmente guardada em ligações que envolvem átomos de fósforo que é um componente tão importante quanto o carbono para que a planta consiga realizar a fotossíntese.

A água exerce um papel interessante na fotossíntese. Para que a energia da luz seja processada, os elétrons vêm da água. A primeira reação que ocorre é a quebra de uma molécula de água formando duas moléculas de hidrogênio $\left(2 \mathrm{x} \mathrm{H}_{2}\right)$ e uma de oxigênio $\left(\mathrm{lx}_{2}\right)$. Portanto, sem água, não pode haver fotossíntese. A água vem lá debaixo, ou seja, da raiz e é transportada para as folhas. A planta é um sistema aberto, ou seja, enquanto parte da água é usada na fotossíntese, uma grande parte é perdida através dos estômatos que têm que ficar abertos para deixar entrar o $\mathrm{CO}_{2}$. Portanto, para poder obter energia, a planta tem que perder água. Transportar água constantemente das raízes para o topo da planta é importante porque os nutrientes (cálcio, potássio, fósforo, etc.) vão para cima com esta água. 
Podemos assim considerar que os estômatos abertos e a própria fotossíntese funcionam como bombas que puxam água e nutrientes para cima. As plantas podem ser comparadas a condicionadores de ar, que borrifam vapor de água na atmosfera durante o dia.

Mas o que é mais interessante ainda é que a produção e o transporte dos açúcares e seu bombeamento para baixo levam a sacarose a todas as partes da planta. Esse transporte funciona como uma bomba no sentido inverso. Quando a planta cresce ela consome os açúcares para suprir os processos com a energia que ficou guardada nas ligações entre os carbonos que a fotossíntese fez. É isso que chamamos de respiração, um processo que libera $\mathrm{CO}_{2}$ de volta para a atmosfera.

As duas bombas (para cima e para baixo) estão interligadas na planta e formam uma circulação que liga o solo à atmosfera. Isso é o que possibilita a vida no planeta.

Veja que uma parte do carbono assimilado como $\mathrm{CO}_{2}$ fica na planta como sacarose, outra parte vira amido, e outra vira celulose. Quando um átomo de $\mathrm{C}$ vira sacarose e é transportado e respirado rapidamente, podemos dizer que o $\mathrm{C}$ deu um "passeio rápido" pela planta e voltou à atmosfera. Nesse caso, o sequestro de carbono de curtíssimo prazo. Quando o C fica armazenado alguns dias ou até alguns meses (no caso das plantas que perdem as folhas durante o inverno) como amido o sequestro de carbono é mais longo. Mas quando o $\mathrm{C}$ vai parar na celulose ele fica guardado no tronco da árvore pelo resto da vida da planta. Esse é um tipo de sequestro de carbono que é característico das árvores e é por isso que elas são tão importantes no contexto das mudanças climáticas globais.

A fotossíntese acontece de dia (nas árvores), somente enquanto há luz acima de um determinado nível. O uso do amido que foi guardado geralmente ocorre à noite, de forma que quando amanhece a planta já degradou parcial ou totalmente o amido, transformou-o em sacarose e transportou-o para outras partes.

Para que a planta se mantenha viva, seu balanço "econômico" tem que ser mantido "no lucro" ou com "perdas mínimas". O que ocorre com várias espécies de árvores da Mata Atlântica e do cerrado é que durante o inverno chove muito pouco e com isto o transporte de água cai drasticamente. Como sem água não dá para fazer fotossíntese, mesmo que haja luz, muitas espécies jogam fora as folhas total ou parcialmente. Isto faz que o metabolismo desacelere consideravelmente. Porém, quando a água volta a fluir, a produção de novas folhas exigirá carbono energia. Como não há folhas, para fazê-las a planta lança mão das reservas de amido guardadas "na poupança" (geralmente nos ramos) no fim último período favorável. 


\section{Agradecimentos}

Agradeço o estimulo e as discussões sobre a importância das árvores na cidade com os produtores e repórteres do Programa Verdejando da Rede Globo de Televisão, que estimularam a busca de dados para formar uma parte deste artigo. Agradeço também ao repórter Eduardo Geraque cujas perguntas sobre as árvores e o cotidiano inspiraram parte deste artigo.

Nota

l O arquivo excel com os dados originais pode ser obtido em <http://www.prefeitura. sp.gov.br/cidade/secretarias/upload/planejamento/Verde\%2010_2013.xls>. Dados para algumas regiões em que há grande contato com reservas florestais foram excluídos da análise.

\section{Referências}

ANDRADE, J. L.; COELHO JÚNIOR, M.N. A importância dos bairros-jardins na conformação da cidade de São Paulo. Revista de Iniciação Científica, Tecnológica e Artística. Edição temática: Comunicação, Arquitetura e Design, v.3, 2013. Disponível em: <http://www.revistas.sp.senac.br/index.php/ic/article/viewFile/503/443>.

ARZOLLA, F. R. D. P. Florestas secundárias e a regeneração natural de clareiras antrópicas na Serra da Cantareira, SP. 2011 Tese (Doutorado) - Instituto de Biologia, Universidade Estadual de Campinas. Campinas, 2011.

EPA - Environmental Protection Agency. Urban heat islan pilot Project (UHIPP), 1998. Disponível em: <http://www.epa.gov/heatisland/pilot/index.htm>.

BRAZOLIN, S. Biodeterioração, anatomia do lenho e análise de risco de queda de árvores de tipuana, Tipuana tipu (Benth.) O.Kuntze, nos passeios públicos da cidade de São Panlo. 2009. Tese (Doutorado) - Escola Superior de Agricultura "Luiz de Queiroz", Universidade de São Paulo, Piracicaba, 2009.

DOMBRO, D. B. How much carbono does a tropical tree sequester? Tree-nation/ United Nations Environment Programme. 2015. Disponível em: <http://www.tree-nation.com/public/documents/tropical_tree_sequestration_co2_tree-nation.pdf $>$.

FIORAVANTI, C. Entre as paredes de concreto. Revista Pesquisa Fapesp, v.214, p.16$25,2013$.

GILCHRIST, K. Promoting wellbeing through environment: the role of urban forestry Forestry Comission UK, 2015. Disponível em: <http://www.forestry.gov.uk/pdf/ Trees-people-and-the-buit-environment_Gilchrist.pdf/\$FILE/Trees-people-and-the-buit-environment_Gilchrist.pdf>.

KLINE, J. R.; MARTIN, J. R.; JORDAN, C. F.; KORANDA, J. J. Measurement of transpiration in tropical trees with tritiated water. Ecology, n.51, p.1068-73, 1970.

MAGRIN, G. O. et al. Central and South America. In: BARROS V. R. et al. (Ed.) Climate Change 2014: impacts, adaptation, and vulnerability. Part B: Regional aspects. Contribution of working Group II to the Fifth Assessment Report of the Intergovernmental Panel on Climate Change. Cambridge; United Kingdom; New York: Cambridge University Press, 2014. p.1499-1566. 
MARENGO, J. A.; VALVERDE, M. C.; OBREGON, G. O. Observed and projected changes in rainfall extremes in the metropolitan área of São Paulo. Climate Research, v.57, p.61-72, 2013.

MARTINI, A. Microclima e conforto térmico proporcionado pelas árvores de rua na cidade de Curitiba - PR. 2013. Dissertação (Mestrado) - Universidade Federal do Paraná. Curitiba, 2013

NOWAK, D. J. et al. Modeled PM2.5 removal by trees in ten U.S. cities and associated health effects. Environmental Pollution, v.178, p.395-402, 2013.

NOWAK, D. J. et al. Tree and forest effects on air quality and human health in the United States. Environmental Pollution, v.193, p.119-29, 2014.

RUNFOLA, D. M.; HUGHES, S. What makes green cities unique? Examining the economic and political characteristics of the grey-to-green continuum. Land, v.3, n.1, p. 131-47, 2014.

SAGAR, R.; RAGHUBANSHI, A. S.; SINGH, J. S. Tree species composition, dispersion and diversity along a disturbance gradiente in a dry tropical forest region in India. Forest Ecology and Management, n.186. p.61-71, 2003.

SALDIVA, P. Os efeitos das mudanças climáticas sobre a saúde humana. In: BUCKERIDGE, M. S. (Ed.) Biologia e mudanças climáticas no Brasil. São Paulo: Rima, 2008. p.227-32.

SMVMA - Prefeitura de São Paulo. 2012. Disponível em: <http://www.prefeitura. sp.gov.br/cidade/secretarias/upload/planejamento/Verde\%2010_2013.xls>.

STERMAN, J. D. Sustainin sustainability: creating a systems science in a fragmented academy and polarized world. In: WEINSTEIN, M. P.; TURNER, R. E. (Ed.) Sustainability science: the emerging paradigma and the urban environment. New York: Springer Verlag NY, 2012. p.21-58.

RESUMO - As árvores urbanas têm grande importância em vários aspectos da vida das cidades, influenciando no conforto térmico e psicológico, filtrando a poluição e ajudando a umidificar a atmosfera urbana pela formação de "rios aéreos". Neste artigo, utilizamos a cidade de São Paulo como modelo para discutir questões relacionadas ao potencial de influência que as árvores urbanas podem ter em todos os aspectos mencionados e também o potencial de inclusão da arborização em ganhos econômicos pela cidade. Tudo isso só pode ocorrer caso a arborização urbana seja planejada com base científica e usando uma abordagem sistêmica que integre as árvores aos processos da cidade. Utilizando dados da prefeitura sobre a porcentagem de verde por habitante, mostramos o déficit arborização que existe principalmente nas zonas leste e central e merecem atenção para planejamentos futuros. Apontamos a importância que as árvores podem ter em produzir vapor de água em dimensões comparáveis às vazões dos rios Tietê e Pinheiros. Finalmente, alguns pontos que devem fazer parte de um plano de arborização que integre as florestas do entorno da cidade com a vida urbana, tendo como pano de fundo a necessidade de uma visão sistêmica que leve em consideração a arborização urbana nas cidades paulistas.

PALAVRAS-CHAVE: Árvores urbanas, Florestas urbanas, Água, Fotossíntese, Metrópoles, Pensamento sistêmico, Poluição, Ilhas de calor, Mudanças climáticas, São Paulo. 
ABSTRACT - Urban trees are highly important for several aspects of the city life, influencing the thermal and psychological comfort, filtering pollution and helping to keep air humidity forming "aerial rivers". In this article, I use the city of São Paulo as a model to discuss issues related to the potential influence of urban trees on the above-mentioned aspects and also the potential of inclusion of urban trees in the context of the economical performance of the city. All this can only happen if urban trees are planned on a strong scientific basis using a systems thinking approach that will help to integrate trees into the city processes. Using data from the City Council (Prefeitura da Cidade de São Paulo) on the index of green per inhabitant, I show that there is a deficit of trees in the Central and East side of São Paulo that deserves attention when planning for the future. I also point out the importance that urban trees have due to the production of water vapor to an extent comparable with the two main rivers in town (Tietê and Pinheiros). Finally, I raise some points that need to be part of the first steps of a plan for urban trees management that should be capable to integrate urban forests with urban life. All that has to be based on a systemic vision that would take into consideration the existence and role of urban trees in cities of the State of São Paulo.

KErWORDS: Urban trees, Urban forests, Water, Photosynthesis, Megacities, Systemic thinking, Pollution, Heat island, Climate change, São Paulo.

Marcos Buckeridge é professor no Instituto de Biociências, Departamento de Botânica, Laboratório de Fisiologia Ecológica de Plantas, Universidade de São Paulo.

@-msbuck@usp.br

Recebido em 25.6.2015 e aceito em 6.7.2015.

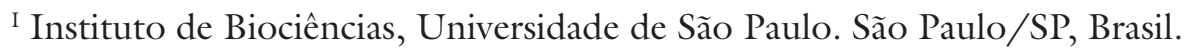


